\title{
Building a Virtual Framework to Exploit Multidisciplinary Project Workshops - peaks \& pits
}

\author{
Márta Turcsányi-Szabó, Andor Abonyi-Tóth and \\ NiKoletta EkKeR
}

\begin{abstract}
Multidisciplinary project work in connection to industry is highly favoured at University education, since it prepares students to envision their spectrum of profession, to be able to participate in production projects in co-operation with partners out of campus, and learn to communicate between disciplines. An effective combination presumes selection of right partners, set-up of proper virtual platform to bridge time, space, and differences in working styles. The set-up process requires several phases of design-based research proofing the melding process to produce a productive workshop that is sustainable. The paper describes the review of literature, the platform and set-up established, a first phase in bridging Art and Computer Science through the description of MOMELTE project, a critical evaluation in order to learn from mistakes, and a new list of design principles to improve the next phase of the workshop process.
\end{abstract}

Key words and phrases: technology enhanced learning, immersive education, virtual worlds, mixed realities, interactive media, serious game design, platform for multidisciplinary projects.

ZDM Subject Classification: B10, U10, C20, C60, B60.

\section{Introduction}

The Faculty of Informatics at Eötvös Loránd University plans to launch its Multimedia M.Sc. and in order to prepare an industry-wise popular set-up, courses have to be blended into an interdisciplinary research \& production workshop for developing innovative interactive media products that could well be accepted within the e.g. museum industry and also produce good publications. In

Copyright (C) 2013 by University of Debrecen 


$$
\text { "tmcs-turcsanyi" — 2013/9/27 — 0:30 — page } 148 \text { — \#2 }
$$

order to design such a workshop a triple of Art \& Computer Science \& Museum Industry has to be combined on the long run, to be able to speak each other's language, communicate on needs, tools, and aesthetics, set-up a platform for the workshop scenario, and operate this integrated process in a sustainable way. As our aim is to enable the workshop to be involved in developing immersive environments as well, it is inevitable that participants should experience and get acquainted with virtual 3D worlds, thus we had to:

(1) Establish the internal frame of the continuous workshop based on on-going courses at our Faculty (and beyond if possible) in order to integrate project work (http://tet.inf.elte.hu).

(2) Exhibit all relevant edutainment developments throughout our campus in order to demonstrate to students the use of these installations within their everyday life and allow them to explore, enjoy and raise their interest to participate in similar projects [1].

(3) Build out the infrastructure to allow collaboration of courses with different settings, timing \& place, credit, theme, and co-coordinator in order to facilitate a virtual laboratory for integrated projects.

(4) Build out a platform \& methodology for collaborating with museums in order to allow the flow of ideas and innovation to converge into distinct projects with our internal frame workshop of courses.

(5) Build a platform \& methodology to disseminate our works and allow as much as possible to enter the world of public education in order to raise interest of future students and mentor teachers in using innovative technology for educational purposes [2].

We shall elaborate on No. 3 \& 4 . We use design-based research, which assumes that context affects learning, offering a methodological tool kit to systematically and iteratively test and improve a designed learning environment and to generate theory alongside in form of design principles [3]. Considering the characteristics and affordances of virtual worlds, an adaptation was proposed to be used for virtual world research projects [4], iterating cycles of implementationsfindings-implementations.

We plan to monitor activities of participants on several levels: analysing log files within OpenQwaq using data-mining on the web access of the portal, Google Analytics with individual variables to investigate users' activities. After the end of the project, users shall fill out a questionnaire, which contains open and closed questions (using a 5 level Likert scale) about their collaborative impressions in 
"tmcs-turcsanyi" — 2013/9/27 — 0:30 — page 149 — \#3

mixed environment. We intend to make improvements to our mixed environment after analysing feedback and monitoring data. After that we plan to evaluate the efficacy of our collaborative environment using the Four Dimensional Framework (Learner specifics, Pedagogy, Representation, Context) and analyse findings in comparison to those found in similar set-ups using Second Life [5].

Our paper describes our efforts and results towards the next phase of our design-based research in producing the workshop platform. Firstly, we review literature on different possibilities for using virtual worlds effectively in higher education, narrowing the spectrum towards the requirements needed for interactive media design and development. Secondly, we describe our design considerations when choosing a virtual platform, taking into consideration the design efforts, social learning theory, our reasoning for choosing OpenQwaq. Thirdly, we describe our efforts in bridging Art and Computer Science projects, successes and failures, to conclude with lessons learned. Fourthly, we investigate internal shortcomings in form of a survey in order to analyse communication skills of Computer Science students in order to be able to design a next generation of virtual platform to embrace the triple of Art, Computer Science, and Museum industry as a workshop for sustainable production.

\section{Virtual worlds in higher education - narrowing the spectrum}

Educational use of MUDs (Multi-user Dimensions/Dungeons) and MOOs (Multi-Object-oriented MUDs) go back to the early 90's, while MMORPGs (Massively Multiplayer Games) appeared about a decade later, like Second Life (http: //secondlife.com/ 2003 by Linden Lab), which soon grew into the largest 3D community, that was exploited for educational use [6]. As time progressed, researchers identified it's use and potential problems when using Second Life in education, including issues with the Second Life software and hardware requirements, a steep learning curve, and the possibility of students becoming exposed to distractions or inappropriate content, nevertheless it is potential for learning did not seize. Potential uses of Second Life include role-play, game and simulation creation, implementation within distance education programs, and the ability to encourage student-centred learning activities [7].

Generally, research on virtual worlds is more and more increasing and results indicate that virtual worlds are mainly used for the simulation of space, used in different ways depending on discipline and temporal scope, they are increasingly 


$$
\text { "tmcs-turcsanyi" — 2013/9/27 — 0:30 — page } 150 \text { — \#4 }
$$

being used in blended learning contexts and due to their most significant communication possibilities, language learning is one of its most popular and successful topic in education [8]. The use of Second Life in higher education has always lead to an impasse between the advocates and the critics [9]. There is still a great deal to learn about how Second Life can benefit higher education. As is common among new technologies, it still appears to be in a largely experimental phase, which might never end [10]. The findings suggest that the 3D virtual world environments produces both positive (through telepresence, a specific aspect of flow, as well as enjoyment) and negative effects (due to distraction-conflict theory in which attentional conflicts faced by users of a highly interactive and rich medium result in distractions) on brand equity when compared to 2D environments [11]. From the student's perspective (and even despite technical difficulties), they commented positively, but did not prefer it over traditional ways of group-work (not feeling the sense of formality) and most of them perceived Second Life as an entertainment environment and preferred the more familiar web-based technologies such as Blackboard for group-work [12].

SLOODLE (Simulation - Linked Object Oriented Dynamic Learning Environment) appearing in 2006 soon linked with the most popular open-source LMS (Learning Management System) Moodle (Modular Object-Oriented Dynamic Learning Environment) producing a braid for higher education that incorporated most of the crucial educational requirements formalised [13]. The Association of Virtual Worlds presents over 375 virtual worlds including their web addresses and brief descriptions for all ages and purposes: MMORPGs, social networks, mobile applications and custom worlds [14]. They also listed over 150 solutions which are used by businesses and organisations to launch and extend their brands as well as for meetings, recruiting, and training [15].

As we are mainly interested in involving our computer science students to take part on-line in interdisciplinary production workshops, we are not so much interested in virtual environments for their social nature, but rather interested in task oriented virtual environments that not just could be used for small collaborative meeting and networking, but also for sharing documents \& knowledge, productivity tools for co-creating, visualising and presenting ideas \& projects, as well as consulting. Besides, we wish to make sure that our projects do not pause a financial burden on us, thus we have to filter all commercial products and stay with open-source versions, which rather limits the spectrum, yet, some good benchmarking could be found by ProViWo project site [16]. 
"tmcs-turcsanyi" — 2013/9/27 - 0:30 — page 151 — \#5

\section{Design considerations for choosing a virtual platform}

It is well worth to look into the investigation of design effort to stage the particular collaboration vs. 3D added value affecting the quality of learning outcomes based on the classification of collaboration and learning pattern. Our choice was on the Quick win design having 3D experience as natural solution with seamless patterns, where simple elements (different file types and video/slides) can be presented, users can have interaction with them and with each other and the 3D added value requires only low design efforts [17].

Though there are some rules that need to be stated, one can learn fairly easily what can or cannot be done in-world by observing the behaviour of others. Despite the fact that virtual worlds are often used effectively in education, in some cases there may be problems which can go to the expense of effective learning. Our choice for OpenQwaq as collaborative environment for common project work was made according to the following analysis [18]:

- Second Life has a steep learning curve, offers plentiful experiences which might distract learners from their main tasks, and emotions/reactions can only be transmitted using the built-in symbolism that can be controller by the user, but that does not reflect true emotions. It also needs quite a budget to set-up, maintain and update with resources needed to establish a sound pedagogic environment for the types of interactions required for the success of our project.

- OpenSim is much more cost effective, however it needs dedicated hardware, professional set-up, administration and maintenance, as well as designers and programmers to build resources in-world. But at the Faculty of Informatics, seeking the proper hardware is not problematic and neither is administration of the complete set-up. Building resources in-world is an interesting activity that could also distract attention from the task of collaboration on projects.

- OpenQwaq needs also hardware and set-up (much more than OpenSim, as it was released on May 2011 and does not have a robust developers' community as background support). The platform can also be used as a file server allowing collaborative work on a client $2 \mathrm{D}$ portal or by entering the $3 \mathrm{D}$ world, getting immersed in the full environment, the same resources could be found and 'touched' for interactions. One can develop as many rooms as needed per teams with just a matter of duplication, which could then be configured for each group. It has most of the interactive features that the other two provides: text chat, voice over IP, teleporting, interactive panels, ... etc and 


$$
\text { "tmcs-turcsanyi" — 2013/9/27 — 0:30 — page } 152 \text { — \#6 }
$$

soon video streaming will be integrated too. Besides, the interactive features accessible on panels provide much higher level of interaction which is a virtue in collaboration. Although avatars cannot be configured the video signal can be projected onto the face of the avatar (when video streaming is integrated), providing feedback on emotional reactions, which is not possible in the above two worlds.

\section{Bridging arts and computers science projects}

\subsection{Common Project on Developing Serious Games}

Moholy-Nagy University of Art and Design (MOME http://www.mome.hu/) is a small, traditional art and design university, with students excelling in visual design and creativity in different disciplines, including Media Design, Eötvös Loránd University (ELTE http://www.elte.hu/) is a big old general university, with several Faculties, including Informatics. MOME's Creative Technology Lab and ELTE T@T lab (http://tet.inf.elte.hu) has a strong motivation to join forces, due to the fact that the former's profile is media design while that of the later is media programming, thus the two produce a braid supplementing each other to produce creative edutainment and museum technologies. The MOMELTE project (co-operative project between MOME and ELTE universities) was launched to build Serious Games in form of a competition. The MOMELTE portal (http://tet.inf .elte.hu/momelte/) provides links to comprehensive descriptions of the project itself and the technology used. Some predefined courses at both universities set their aims to take part in this project specifically.

\subsection{The Setup for bridging}

Probably the most difficult part of the co-operation is synchronising communication and monitoring collaboration:

- Having different technological backgrounds and use of tools, students need to be introduced to technology through their own experiences in order to raise attention to new developments allowing emergence of innovative ideas.

- Informatics students are highly disciplined and use different technologies for sharing files, but are less communicative. On the other hand, art students are more philosophical and refer mainly to Raison D'être. 


$$
\text { "tmcs-turcsanyi" — 2013/9/27 — 0:30 — page } 153 \text { — \#7 }
$$

- The timing of different courses cannot be synchronised, so real-time or synchronous meeting is quite difficult to achieve.

\subsection{Introducing Step-wise Immersion}

We have devised a new methodology for immersing our students into mixed realities step-wise (Prezi: http://bit.ly/KXnLBF), by experiencing museum technology, being precise and concise, respecting deadlines, using social media, getting to know collaborative technologies, developing an inventory of common vocabulary for discussions, being able to find own added values to supplement each other, documenting feedbacks/steps taken, getting more and more immersed in virtual reality by shifting collaboration towards this area and developing experiences that could lead to innovation of ideas useable in museum context.

Students used their own Learning Management Systems within their own university courses that they were already accustomed to and we set up a $3 \mathrm{D}$ OpenQwaq platform for collaboration (allowing its use in 2D as file server) and for one specific project theme we set up an OpenSim server to allow development of a virtual campus for the future. We also developed a Google Sites area as an alternative workspace for those finding it difficult to use the newly developed environment with more immersive features, however this provided only basic tools: area for definition of project and access to participants, file area (to exchange project files), memo area (to document meetings and agreements), discussion area (for asynchronous conversation). Apart from these, we also used a multitude of innovative technologies throughout the process [19].

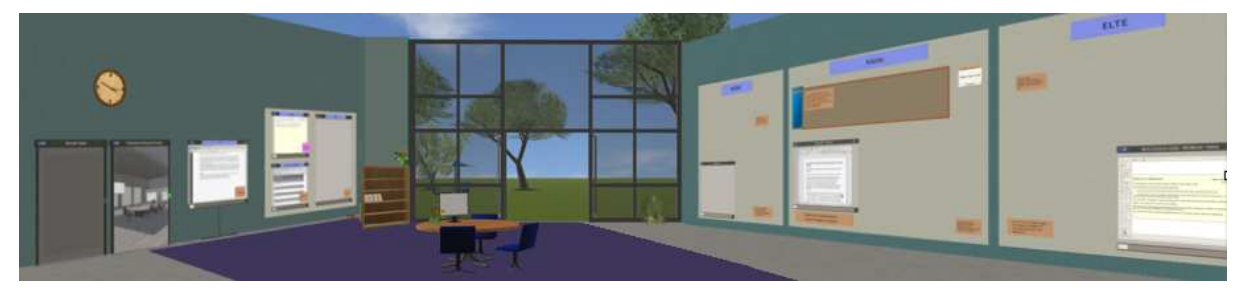

Figure 1. OpenQwaq - project room template for MOMELTE project

Our OpenQwaq world has a Gallery for social activities displaying products of former projects. Each project group is provided with a separate room for collaboration (and outdoors leisure activities), including a communication board with group tweets being piped in-world, white boards and all the above interactive collaboration functionality that is also available in the Common Area. The 


$$
\text { "tmcs-turcsanyi" — 2013/9/27 — 0:30 — page } 154 \text { — \#8 }
$$

rooms are built to illustrate a comfortable working environment, but students are encouraged to change and create new artefacts to increase their own comforts.

\section{Results and lessons learned}

The final results and products of this workshop were quite remarkable, with the museums being very satisfied, getting some rather good models for their exhibits that could be further polished and finalised [20]:

- AR music book and Kinect music and motion game illustrating one of the most popular plays for children called Aunt Bors - most successful!

- Augmented walk experiencing the works of famous artists in town for Petőfi Literature Museum.

- Simulation of pandemics and the path of food for the Semmelweis Museum for History of Medicine.

- Microsite for Kolibri Theatre.

- AR video explanations on pictures of modern Art at Ludwig Museum.

- Creating a virtual exhibition area in OpenQwaq and OpenSim.

Aunt Bors book and interactive application was commissioned by Bajor Gizi Actor's Museum for the 20th jubilee of the Kolibri Theatre. A true MOMELTE co-production with highlight on the charming graphic design of Manja Lekic http://bit.1y/17wFxDu which was brought to life with augmented reality technology by Tamás Matuszka http://bit.1y/13jacDk to play the music when camera recognises pictures and animated with Flash by Zénó Szabó to be controlled using Kinect by Dániel Szabó and Tibor Gortva to bewilder children http://bit.1y/16tCAEY at the museum and theatre. The book was also presented in Newcastle at Designing Interactive Sytems and in Hampshire Massachussetts at Non-visible and Intangible Artists Books respond to E-books.

However the process itself was rather painful, as we had to realise that though teachers at MOME in theory promote the use of social networks and high tech environments, they are not so fluent with these innovative artefacts to be able to support their students with their use. Even though we have offered our help on spot to MOME at every step, they were far too busy with project development, that they could not find time to accept our help. After all our invested efforts, we have to frankly admit, that our fine-tuned Step-wise Immersion process ended up as step-wise Murphy process (what can go wrong - goes wrong): 
- ELTE students were registered to Twitter, awaiting ideas and discussions, however MOME teachers misunderstood Twitter functionality and finally gave up enforcing it onto their students - thus teachers had to arrange themselves teamings for projects.

- ELTE teachers made sure to find partners for most of the projects initiated by MOME, however MOME teachers did not find it important to do like-wise as their policy is endorsing the creativity of their own students - thus only projects initiated by MOME were supported, which (even though completed successfully) did not have the zest of innovation, which would have been the aim of ELTE in order to write good scientific publications on results.

- Face-to-face meetings for project teams were extremely difficult to arrange, thus the projects' launch timing had to be prolonged by two-three weeks due to unsynchronised holiday intervals at both universities.

- Due to an unforeseen bug in OpenQwaq (related to the use of central-European characters) system access was paralysed for days, even though we spent incredible effort in solving the problem, but found no support or similar problems in the community portal and could only solve it with delay - thus MOME was discouraged at using the OpenQwaq client to access the 2D file server and we had to set up quickly the alternative Google Sites working area, where each project group had their own area for discussion, blogging, forum and file exchange.

- Even though we tested the 3D OpenQwaq virtual platform before launching the project, MOME teachers were using their own laptops at test time and had a good impression on its use, however when using their Mac lab at project time, they realised that OpenQwaq had several problems running on their computers (ELTE had no problems as our Mac lab had brand new machines) - thus we urged only those student groups to use the 3D world, where everyone had equal access to the area. Slowly everyone shifted to the common Google Sites platform, not to spend extra time with the needed learning curve of the $3 \mathrm{D}$ environment.

- ELTE being technology oriented was quite aware of the necessary investment from the side of students and staff credit-load-wise, however MOME was inexperienced in this respect and students started to complain about the extra load that was not rewarded in credits for their extra technology use an increase in their credits was endorsed later on, but MOME students were a bit discouraged by that time. 


$$
\text { "tmcs-turcsanyi" — 2013/9/27 - 0:30 — page } 156 \text { — \#10 }
$$

However, we must state, that even though we had tons of problems to solve on the go, our efforts were rewarded by the end-products produced by students works, some of which even ending in conference papers, demos, and launched museum exhibits. We could not perform our research, analytics, surveys as planned, but had to rethink our strategy and look at ourselves in a critical manner: would have we succeeded with this platform if the problems of technical knowledge, technical set-up and support were as good at both sides? That is to say: what about our own students? Are they enough literate in social networks? Are they ready to collaborate on such platforms? How about their communication skills: are they good enough for multidisciplinary project work? We decided to end our investigation by trying to answer these questions before composing our design principles that should conclude this first phase of design-based research.

\section{In-house investigation on on-line and virtual tools}

We made a survey among our own students $(\mathrm{N}=342)$, attending courses on B.Sc. or M.Sc. level as program designer students within our Faculty of Informatics, asking them the following questions:

- Which social media sites do they use and with what frequency?

- During project work, which forms of communication do they prefer?

- What are their needs concerning project support environments?

- What is their self-esteem about their own communication skills and if they had a chance would they wish to improve them?

We measured the frequency of social media use on a 5 scale Likert scale $(1=$ Never, $2=$ Rarely, $3=$ Sometimes, $4=$ Often, $5=$ Very often). In the following Table 1 we present results according to the mean values of frequency of use of social media sites in a descending order.

We can see that Youtube and Facebook are the two most popular social media sites used by students. The mean frequency value for the rest of the sites is under 2. Investigating the use of the relatively new Pinterest community site we found that students were not so much interested (maybe did not even know about it) commenting that they "prefer to use community sites, where most of their acquaintances could be reached". This could be partly one of the reasons why the use of Google+ is not so popular. It seems that until the number of acquaintances in the community does not reach a critical number, active use is 


$$
\text { "tmcs-turcsanyi" — 2013/9/27 — 0:30 — page } 157 \text { — \#11 }
$$

Table 1. Frequency of social media use

\begin{tabular}{|l|c|c|c|c|}
\hline & Mean & Std. Deviation & Variance & Mode \\
\hline 1. Youtube & 4,01 & 0,835 & 0,698 & 4 \\
\hline 2. Facebook & 3,89 & 1,259 & 1,584 & 5 \\
\hline 3. Google+ & 1,76 & 1,030 & 1,061 & 1 \\
\hline 4. Iwiw (Hungarian net) & 1,59 & 0,690 & 0,477 & 1 \\
\hline 5. Twitter & 1,43 & 0,889 & 0,791 & 1 \\
\hline 6. Virtual, 3D environ. & 1,16 & 0,493 & 0,243 & 1 \\
\hline 7. Linkedin & 1,14 & 0,461 & 0,213 & 1 \\
\hline 8. Pinterest & 1,03 & 0,208 & 0,043 & 1 \\
\hline
\end{tabular}

not typical. It is also quite evident, that the use of $3 \mathrm{D}$ virtual environments is not at all characteristic; they do not have prior knowledge of such.

Table 2. Frequency of communication services use

\begin{tabular}{|l|c|c|c|c|}
\hline \multicolumn{1}{|c|}{ Service } & Mean & Std. Deviation & Variance & Mode \\
\hline 1. Instant messaging & 3,77 & 1,153 & 1,330 & 5 \\
\hline 2. Reading forum posts & 3,51 & 0,974 & 0,949 & 3 \\
\hline 3. Liking Other's Posts & 2,82 & 1,088 & 1,183 & 3 \\
\hline 4. Comment Other's Posts & 2,73 & 1,068 & 1,141 & 3 \\
\hline 5. Voice calls over the internet & 2,69 & 1,296 & 1,681 & 3 \\
\hline 6. Sharing activities/news & 2,64 & 1,101 & 1,211 & 3 \\
\hline 7. Writing forum posts & 2,41 & 1,009 & 1,017 & 2 \\
\hline 8. Comment non-anonymously & 2,34 & 1,011 & 1,021 & 2 \\
\hline 9. Video calls over internet & 2,29 & 1,219 & 1,485 & 1 \\
\hline 10. Comment anonymously & 1,73 & 0,858 & 0,737 & 1 \\
\hline 11. Writing a blog post & 1,54 & 0,848 & 0,718 & 1 \\
\hline
\end{tabular}

Our survey on the use of different communication services, using the same Likert scale Table 2 shows results according to decrease of use of services.

It can be seen, that among the synchronous communication forms chat is the most popular $(3,77)$, followed by voice call $(2,69)$, and video call $(2,29)$. As for the asynchronous communication forms, reading forums is the most popular $(3,51)$, and the least popular is writing blogs. Among the students who filled out the surveys, just $3 \%$ declared themselves to be frequent bloggers, thus it seems that this form of self-expression is negligible among programmers.

We also asked students which forms of communication would they prefer within a collaborative project work. We present the results in Table 3, listing the forms according to the mean value of preference in a descending order. The values of the Likert scale are $(1=$ Very improbable, $2=$ Probably Not, $3=$ Possibly, $4=$ 
Probably, $5=$ Very Probably). The survey also allowed a free form to comment on students' favourite types of communication.

Even though it is clear from Table 3, that students prefer face-to-face communication in project work, we are aware from previous project set-ups that it is rather difficult to find a common time and place for meetings, due to the fact that students taking part in our internal projects (attending courses within our own Faculty) have different time schedules for courses and other activities. Thus it would be rather impossible to arrange a common meeting for those working in different institutes and fields. In order to arrange regular communication, we definitely have to make use of innovative synchronous communication tools, like voice or video conferencing. It might well be, that some of the participants could not take part even in this way, so it is necessary to provide recordings of such sessions to be viewed or heard later and also to prepare reminders in form of text.

Table 3. Preferred communication forms

\begin{tabular}{|l|c|c|c|c|}
\hline \multicolumn{1}{|c|}{ Contact by... } & Mean & Std. Deviation & Variance & Mode \\
\hline 1. Personal meeting & 4,51 & 0,776 & 0,603 & 5 \\
\hline 2. Email & 3,87 & 1,001 & 1,002 & 4 \\
\hline 3. Chat & 3,70 & 1,075 & 1,157 & 4 \\
\hline 4. Voice over IP & 3,68 & 1,183 & 1,399 & 4 \\
\hline 5. File sharing (Dropbox) & 3,55 & 1,157 & 1,339 & 4 \\
\hline 6. Shared document editing & 3,49 & 1,161 & 1,347 & 4 \\
\hline 7. Closed social network & 3,49 & 1,093 & 1,195 & 4 \\
\hline 8. Telephone/mobile phone & 3,32 & 1,111 & 1,235 & 4 \\
\hline 9. Internet video calls & 3,21 & 1,283 & 1,646 & 4 \\
\hline 10. Open social network & 2,50 & 1,143 & 1,306 & $3^{*}$ \\
\hline 11. Virtual 3D environ. & 2,18 & 1,321 & 1,746 & 1 \\
\hline
\end{tabular}

It is also evident that emails are the next most popular forms of communication. However we can see this form of communication to be very critical in case of project development and monitoring, as we are not able to trace students' work. A solution could be to provide internal mailing within the collaborative platform, and allow participants to use only this traceable form during project work. Thus, analysis of $\log$ files could provide us information to determine the frequency of activities and the level of contribution of individuals.

After emails, chat is the most popular. From free form comments, we could see that it is an important factor among "chat fans" that they could do so independently and in parallel with several acquaintances at the same time. Many

* Multiple modes exist. The smallest value is shown. 
"tmcs-turcsanyi" — 2013/9/27 - 0:30 — page 159 — \#13

students indicated, that Facebook is their chosen main communication platform, because it provides them the fastest form of communication, supporting both message and chat function, while they can access most of their acquaintances. At the same time, a lot of students expressed their dissatisfaction with the huge amount of junk information, Facebook being too noisy channel at the same time.

Those who indicated video conferencing to be their favourite form of communication declared parallel transfer of gestures and mimics as an important factor, making information transfer to be less misunderstandable (which could be so in case of lack of emoticons in services). We can also see that some students find video conferencing inconvenient, as they "prefer to hide behind a nick name, not to reveal gender, and only allow the transfer of thoughts".

There were students who declared forums to be the most perfect form of communication, highlighting the fact (in contradiction to chat) that it is not necessary to answer immediately, but they could think more deeply before having to give an answer and could also refer to previous posts of others (that could be followed in a more structured form than in case of emails) to take into consideration the opinion of others before composing that of their own.

The survey also allowed students to rate their communication skills on a 5 scale Likert scale. We were also interested to know, whether they were ready to take a free course at our faculty on developing their own communication skills.

Most of the students considered themselves having good communication skills (4 on the scale), while the mean value being 3,68 . The motivation in taking part on communication training indicated a mean value of 3,35. Nevertheless, there is a slightly positive correlation between those who wish to participate on communication training and the level of their declared abilities, that is: those who are willing to be involved in communication training are mainly those who believe they have good communication skills. It might well be that those who declared themselves to have poor communication skills do not even find this skill to be so important, even though it seems they do need it the most. It is thus highly recommended to test communication skills (not just technical skills) before entering multidisciplinary project work.

The answers from students raised our attention to the need for use of VCS (Version Control System) integrated within our communication platform (especially important for programmers, but not outside of the general platform).

During our previous longitudinal studies within an integrated course involving program designer and informatics teachers learning about "Designing multimedia materials" to develop artefacts in groups of four as project work we analysed
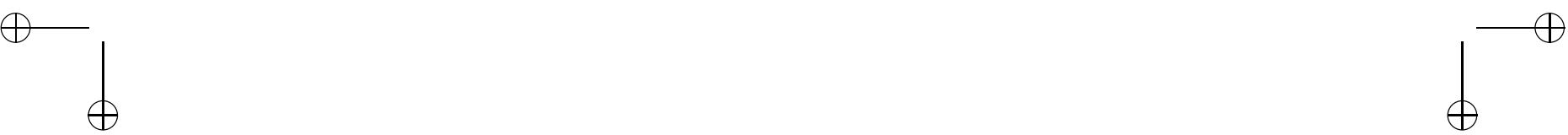


$$
\text { "tmcs-turcsanyi" — 2013/9/27 — 0:30 — page } 160 \text { — \#14 }
$$

student's behaviour and attitude in an online learning environment and examined the learning styles of students on different scales. Our previous findings have some relation to those experienced in this project [21]

- Though learning styles are highly debated, we were able to show some typical traces of similarities in programmer and informatics teachers.

- At the same time there should also be a slight difference between the two with respect to communication skills, as project communication proved to be problematic if only programmer students took part in the course.

Thus, we have to integrate all our findings into new design principles as a conclusion of this research in order to be able to take the next step to set-up a new platform for multidisciplinary workshop.

\section{Design principles}

We thus come to the point of formulating our next design principles:

- Since our main aim is to design and develop innovative artefacts, that not only qualify as a museum installation, but could produce research publications, we have to make sure that our own project ideas are definitely incorporated in the next process of project work. Thus, we plan to make direct connections with museums and work out topics that suit both partners beforehand.

- No matter how our project partners declare their knowledge and skills with use of technology and social media, we have to make sure that it is actually up to our expectations and endorse a starting phase for levelling the knowledge needed for fluent project communication.

- We have to make sure at the beginning of the semester that we start with familiarising our own students with the social media tools needed and try to integrate third party tools within our communication platform.

- We have to make sure in the very beginning that we identify difficulties in communication skills among our students and make sure to build in training elements within our courses to develop these skills as well.

- We have to choose a 2D platform for basic communication and force only those project participants into 3D platforms who are specifically entitled to develop such as their project work. The basic platform, however must have all the necessary tools that help project work to emerge with ease and at the 
"tmcs-turcsanyi" — 2013/9/27 - 0:30 — page 161 — \#15

Building a Virtual Framework to Exploit Multidisciplinary Project Workshops

161

same time provide privacy for developments: chat, forum, videoconferencing, file-share, versioning, white-board, desktop share.

- Allowing work to progress in closed circles with respect of each museum seems to be a requirement from the side of museums as they are not so keen in letting their ideas spread, the least to other museums.

- However, we shall definitely put more effort in networking our own internal workshop (integrating different courses) through OpenQwaq and try to investigate further its use in production of creative program artefacts. In the last semester we started to hold some consultation hours within the OpenQwaq platform, which we shall further spread in the next semester, thus making our students feel more comfortable with such.

- We have to make sure that project teams would meet regularly online (no matter which platform used) and create tools that would allow further scheduling and produce a gadget that could be inserted into any browser to show whether someone from the team is on-line.

\section{Conclusion}

Virtual worlds are highly used in Higher Education, though there is still lot to explore on their benefits within the learning process. Lots of different 3D worlds exist for diverse aims, Second Life being the most popular among them, however a careful consideration in design efforts, social learning theory and a specific need for a task oriented virtual environment - that not just could be used for small collaborative meeting and networking, but also for sharing documents \& knowledge, productivity tools for co-creating, visualising and presenting ideas $\&$ projects, as well as consulting - really narrows the scope.

OpenQwaq technology has been chosen as 3D platform, which was released only recently, so there is just an emerging community of developers, apart from the fact that its origin, TelePlace (http://www.teleplace.com/) service has been around for some time. So, we had to live with the hindrance in lack of community support, yet believe that there is much to explore within this virtual world in supporting task-based productive work joining multidisciplinary teams.

We made careful considerations in choosing not only the virtual world but also integrated additional technology to produce a platform where step-wise immersion could be attained in mixed reality in order to enable participants to experience 


$$
\text { "tmcs-turcsanyi" — 2013/9/27 — 0:30 — page } 162 \text { — } 16
$$

and master the use of required technologies for further development of different artefacts with relation to requirements from museums.

By bringing together students of different background and exploiting the artistic, creative approach and the professional ICT knowledge and skills, novel applications came to life in the first phase of the project, however the totally new mode of working together and also striving to satisfy museum requirements has taken away considerable attention from technology requirements and urge to experience the 3D immersive feeling and pulled back even the braver ones to the more consolidated 2D platform.

Re-examining the skills of our own students we found, that even though they are technology minded and find no problems in this field, their use of social media is very limited and their communication skills need much to improve in order to let ourselves go into a next phase of multidisciplinary project research without feeling any guilt in a proper preparation from our own side. Our research, though a bit out of scope, has lead us to recognise some more important design consideration for an effective collaboration platform and priorities in creating primary partnerships. We do look forward to the next phase of our research.

\section{Acknowledgement}

We hereby wish to acknowledge the work of Péter Simon is setting up the OpenQwaq world. The Project is supported by the European Union and cofinanced by the European Social Fund (grant agreement no. TAMOP 4.2.2./B10/KMR-2010-0030) and the EITKIC 12-1-2012-0001 project, which is supported by the Hungarian Government, managed by the National Development Agency, financed by the Research and Technology Innovation Fund and was performed in cooperation with the EIT ICT Labs Budapest Associate Partner Group (www . ictlabs.elte.hu)

\section{References}

[1] M. Turcsányi-Szabó, Augmented Edutainment on campus, in: Proceedings of 2nd Immersive Education Summit, (M. Gardner, F. Garnier, C. Delgado Kloos, eds.), Universidad Carlos III de Madrid Departamento de Ingeniería Telemática, Paris, France, 2012, 204-209, also at http://bit.1y/17uVyK7 (accessed 08.06.2013). 
[2] M. Turcsányi-Szabó, Aiming at Sustainable Innovation in Teacher Education from Theory to Practice, Informatics in Education 11, no. 1 (2012), 115-130, also at http://bit.ly/16txwjW (accessed 08.06.2013).

[3] A. L. Brown, Design Experiments: Theoretical and methodological challenges in creating complex interventions in classroom settings, Journal of the Learning Sciences 2, no. 2 (1992), 141-178.

[4] A. Santos, Using Design-Based Research for Virtual Worlds Research Projects [online, 2011.03.09], Journal of Virtual Worlds Research: The Researcher's Toolbox 3, no. 1 (2010), http://bit.1y/14fBkGp (accessed 08.06.2013).

[5] S. de Freitas, G. Rebolledo-Mendez, F. Liarokapis, G. Magoulas and A. Poulovassilis, Learning as immersive experiences: Using the four-dimensional framework for designing and evaluating immersive learning experiences in a virtual world, British Journal of Educational Technology 41, no. 1 (2010), 69-85, retrieved from http://bit.1y/153hxWE (accessed 08.06.2013).

[6] S. de Freitas and M. Griffiths, The convergence of gaming practices with other media forms: What potential for learning? A literature review, Learning, Media and Technology 33, no. 1 (2008), 11-20.

[7] C. Inman, V. Wright and J. Hartman, Use of Second Life in K-12 and Higher Education: A Review of Research, Journal of Interactive Online Learning 9, no. 1 (Spring 2010), ISSN: 1541-4914 - also at www.ncor.org/jiol (accessed 08.06.2013).

[8] S. H. Kim, J. Lee, K. Michael and M. K. Thomas, Between Purpose and Method: A Review of Educational Research on 3D Virtual Worlds, Journal of Virtual Worlds Research 5, no. 1 (2012), http://bit.1y/1cFjSib (accessed 08.06.2013).

[9] D. K. Herold, Second Life and Academia - Reframing the Debate between Supporters and Critics, Journal of Virtual Worlds Research 5, no. 1 (May 2012), also at http://bit.1y/13WQD2s (accessed 08.06.2013).

[10] K. Bowers, D. Davis and J. Neely, Framing Second Life for Use in Higher Education: An Analysis of EDUCAUSE Review and The Chronicle of Higher Education, Journal of Virtual Worlds and Education 1, no. 1 (2010), 136-165, also at http://bit.1y/11JcVbx (accessed 08.06.2013).

[11] F. Nah, B. Eschenbrenner and D. DeWester, Enhancing Brand Equity Through Flow and Telepresence: A Comparison of 2D and 3D Virtual Worlds, MIS Quarterly, Special Issue: New Ventures in Virtual Worlds 35, no. 3 (September 2011), 731-747, http://bit.1y/16r1C7q (accessed 08.06.2013).

[12] A. Alrayes and A. Sutcliffe, Students' Attitudes in a Virtual Environment (Second Life), Journal of Virtual Worlds Research 4, no. 1, Metaverse Assembled 2.0 (July 2011), also at http://bit.1y/19K5NAA (accessed 08.06.2013).

[13] J. Kemp, D. Livingstone and P.R. Bloomfield, SLOODLE: Connecting VLE tools with emergent teaching practices in Second Life, British Journal of Educational Technology 40, no. 3 (2009), 551-555, also at http://bit.1y/15JGgDt (accessed 08.06.2013).

[14] Consumer Guide to Virtual Worlds, The Association of Virtual Worlds, 2010, at http://bit.1y/16r1JzY (accessed 08.06.2013). 


$$
\text { "tmcs-turcsanyi" — 2013/9/27 — 0:30 — page } 164 \text { — \#18 }
$$

164 M. Turcsányi-Szabó, A. Abonyi-Tóth and N. Ekker : Building a Virtual Framework...

[15] An Enterprise Guide to Virtual Worlds, The Association of Virtual Worlds, 2010, at http://bit.1y/1b8pCzl (accessed 08.06.2013).

[16] Benchmark of 3D virtual environments, Professional Collaboration and Productivity in Virtual Worlds, 2012, at http://bit.1y/12WOw4S (accessed 08.06.2013).

[17] M. Turcsányi-Szabó, L. Csízi and L. Végh, Virtual worlds in education - best practice, design and research considerations, Teaching Mathematics and Computer Science 10, no. 2 (2012), 309-323, ISSN 1589 - 7389.

[18] M., Turcsányi-Szabó, P. Simon, A. Abonyi-Tóth and N. Ekker, Step-wise immersion bridging two universities, in: Proceedings of iED Summit, (J. J. G. Rueda and M. B. I. Espiga, eds.), 2011, 141-150, ISBN: 978-84-89315-66-2, also at http://bit.1y/12WOGJw (accessed 08.06.2013).

[19] M. Turcsányi-Szabó, P. Simon, A. Abonyi-Tóth, N. Ekker and Zs. Ruttkay, Augmenting Experiences - a Bridge Between Two Universities, in: Proceedings of ISMAR 2011, 2011.

[20] MOMELTE Gallery page: http://bit.ly/MOMELTEgallery (accessed 08.06.2013).

[21] I. Béres, T. Magyar and M. Turcsányi-Szabó, Towards a Personalised, Learning Style Based Collaborative Blended Learning Model with Individual Assessment, Informatics in Education 11, no. 1, Vilnius University (2012), 1-28, also at http://bit.1y/14fD0jo (accessed 08.06.2013).

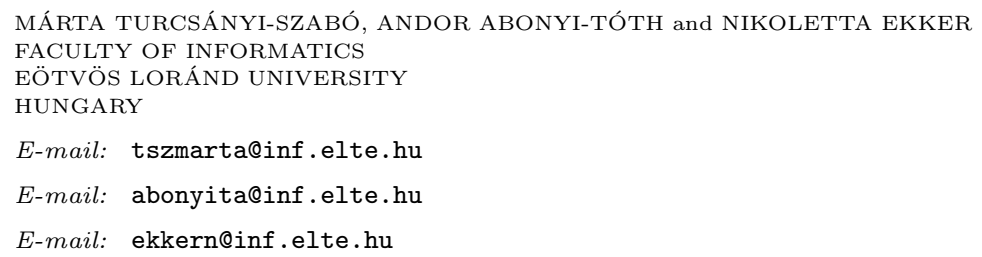

(Received September, 2012) 